\title{
Encontro estágio-escola-universidade: estabelecendo vínculos necessários ao fazer teatral no ambiente escolar
}

\author{
Diego de Medeiros Pereira* \\ Marcia Berselli**
}

\begin{abstract}
Resumo
$\mathrm{O}$ artigo apresenta reflexões sobre práticas artístico-pedagógicas realizadas em Estágios Curriculares na área do Teatro. Para tanto, são problematizados aspectos observados em um evento acadêmico que reuniu estagiários e professores das escolas e da universidade. Além de apresentar abordagens teóricas e metodológicas utilizadas pelos estudantes, aspectos que se mostraram relevantes à realização de processos de ensino/aprendizagem em teatro na escola pública são analisados pelo olhar dos professores orientadores das práticas. As reflexões geradas contribuem para uma maior visibilidade do teatro como ação artística, pedagógica e cultural na paisagem do território escolar, destacando também a dimensão política implícita nas relações universidade-escola.

Palavras-chave: Pedagogia do Teatro; Estágio Curricular; Escola; Práticas Artísticas.
\end{abstract}

\section{Meeting teaching practice-school-university: establishing the necessary links to do theatrical in the school environment}

\begin{abstract}
The article presents reflections on artistic and pedagogical practices performed in Supervised teaching practice in the Theater area. Therefore, aspects observed in an academic event that brought together students, teachers and professors are discussed. In addition to presenting the theoretical and methodological approaches used by the students, the main aspects that were relevant to the realization of teaching/learning processes in theater in the public school are analyzed by the view of the supervisors. The reflections generated contribute to a greater visibility of the theater as artistic, pedagogical and cultural action in the landscape of the school territory, also highlighting the implicit political dimension in the relations between university and school.
\end{abstract}

Keywords: Theater Education; Supervised teaching practice; School; Artistic Practices.

\section{Introdução}

Nos cursos de licenciatura, o Estágio Supervisionado, tradicionalmente, é o componente curricular que promove a efetiva inserção do futuro professor no ambiente escolar. Mesmo que muitos licenciandos participem de programas e projetos de extensão ou iniciação à docência, ministrando oficinas ou conduzindo colegas em processos artísticos, é no período do estágio que o acadêmico é convocado a assumir a função de professor frente a uma turma, inserida em contexto educacional e institucional específicos, bem como responder por determinados conteúdos a serem desenvolvidos com um grupo de estudantes. No processo formativo de um docente em Teatro, esse também é o momento em que o acadêmico experimenta possíveis metodologias de ensino, explorando as amplas possibilidades que tanto as formas tradicionais do fazer teatral quanto a cena contemporânea oferecem para o ensino dessa linguagem.

$\mathrm{Na}$ busca por refletir sobre as práticas desenvolvidas durante os estágios do Curso de Licenciatura em Teatro, da Universidade Federal de

*Endereço eletrônico: diego.pereira@ufsm.br

**Endereço eletrônico: marcia.berselli@ ufsm.br
Santa Maria, e com o intuito de estimular o diálogo entre universidade e escola, os professores das disciplinas de Estágio Supervisionado de Docência em Teatro I e II (Ensino Fundamental e Ensino Médio, respectivamente) organizaram o I Encontro dos Estágios da Licenciatura em Teatro ${ }^{1}$. O Encontro ocorreu no primeiro semestre de 2017, reunindo estagiários das disciplinas de Estágio Supervisionado, professores dos Cursos de Licenciatura em Teatro e Bacharelado em Artes Cênicas e das unidades de Educação Básica da rede de ensino pública de Santa Maria que receberam os projetos desenvolvidos nesse semestre, além de gestores das coordenadorias de educação do município e do estado. Objetivou-se fomentar discussões sobre o fazer teatral no ambiente escolar, ampliando os saberes dos envolvidos sobre as diferentes perspectivas da prática docente em Teatro e a busca pela compreensão das especificidades do seu ensino na escola.

Dentre os objetivos específicos do evento, destacamos o interesse em compartilhar as práticas dos Estágios Supervisionados de Docência I e II, debater as metodologias adotadas no 
desenvolvimento dos projetos, discutir as temáticas exploradas nos diferentes campos de atuação, promover maior visibilidade para as práticas artístico-pedagógicas em Teatro, além da busca por fortalecer os laços com a comunidade escolar.

Neste texto, buscamos compartilhar as principais discussões levantadas nesse encontro, apontando as abordagens utilizadas pelos estudantes em campo, refletindo sobre as descobertas e desafios dessa prática de formação docente, bem como problematizando os principais aspectos que se mostraram relevantes à realização de processos de ensino/aprendizagem em Teatro na escola pública. Acreditamos que se faz necessário ampliar as discussões sobre esses processos, assim como alargar a percepção que os diferentes sujeitos que compõem esses espaços de educação possuem dos trabalhos realizados na disciplina de Artes, sobretudo àquelas que dizem respeito ao Teatro, ainda ausente como linguagem específica em grande parte dos currículos das escolas brasileiras.

\section{Relações universidade-escola}

$\mathrm{O}$ ensino do Teatro, ainda incipiente em muitas redes de ensino públicas do país - inclusive na cidade de Santa Maria, interior do Rio Grande do Sul - é, muitas vezes, carregado de forte visão reducionista de suas possibilidades artísticas e pedagógicas. Na maior parte das escolas de Ensino Fundamental que receberam os estágios do curso de Teatro realizados no ano de 2017, impera o ensino polivalente das artes - desenvolvido, em grande parte, por profissionais formados nos antigos cursos de Educação Artística - ou apenas o ensino de Artes Visuais, ministrado por professores formados nessa linguagem. Nas escolas de Ensino Médio (sob responsabilidade do estado) não é raro encontrar a disciplina de Artes ministrada por professores de outras disciplinas, como forma de completar suas cargas horárias.

Os cursos de formação de professores polivalentes em Educação Artística (nomenclatura anterior à atual Artes) foi resultado de uma demanda inaugurada pela Lei de Diretrizes e Bases da Educação (LDB) 5.692/71 que obrigou, pela primeira vez, o ensino da arte como atividade educativa no currículo escolar brasileiro. Como aponta Ribeiro (1999, apud SANTANA, 2000, p. 8586):

[...] observou-se que na área de Educação Artística estas licenciaturas passaram a formar a nova geração de professores 'polivalentes', descaracterizando o campo de conhecimento autônomo da música, das artes plásticas e das artes cênicas. Este novo campo tornou-se mais transfigurado ainda quando os professores ao transmitirem um mosaico de conhecimentos da área de artes (e de uma forma mais geral o faziam em um contexto abrangente e superficial da realidade sociocultural brasileira), passaram a perceber a desconexão entre os conhecimentos artísticos.

Ainda que os Parâmetros Curriculares Nacionais (BRASIL, 1997) tenham apontado a necessidade de que sejam trabalhadas na escola quatro linguagens específicas - Artes Visuais, Música, Dança e Teatro - o que fortaleceu as Licenciaturas em linguagens específicas da arte, sabe-se que essa indicação, na prática, ainda não está configurada. Segue-se que, em muitas redes de ensino, privilegia-se o ensino das Artes Visuais e contrata-se, via de regra, profissionais formados apenas nessa linguagem para assumirem a disciplina de Artes.

A discussão se amplia ao buscarmos refletir sobre o papel da disciplina de Artes no currículo escolar. De espaço de lazer (como uma extensão do intervalo) à produção de materiais a serem compartilhados nas datas festivas comemoradas na escola, ainda é frágil e instável a compreensão das dimensões do fazer artístico no ambiente escolar. Sendo assim, de modo geral, muitas vezes a disciplina de Artes segue na perspectiva da educação artística, com pais e educandos questionando sua presença no currículo. Em tempos de ênfase no ensino superior, em que a preparação ao vestibular se coloca como parâmetro das propostas pedagógicas desenvolvidas na escola de forma cada vez mais precoce, os discursos contrários à arte são perspectivas preocupantes.

Assim, acredita-se como necessária a ampliação da visão dos profissionais da educação sobre o ensino das diferentes linguagens da arte, sobretudo do Teatro, foco deste texto, e a abertura de concursos públicos para a contratação de profissionais específicos dessa linguagem, que lidem com o fazer teatral com propriedade, para que o cenário atual do Teatro na escola possa ser transformado. Desse modo, cabe também aos futuros professores, que adentram a escola no período do estágio, o compartilhamento sobre seus fazeres e saberes, não apenas com os estudantes, mas com os demais sujeitos que compõem o ambiente da escola. Ainda, como área que engloba diferentes 
perspectivas sobre o fazer teatral, é importante que os professores em formação no campo do teatro aliem o ensino à pesquisa, gerando novas práticas e reflexões sobre o tema.

Segundo Pupo (2005, p. 218),

O avanço da pesquisa no campo da pedagogia do teatro depende, dentre outros fatores, da clareza dos conceitos que a configuram. A reflexão sobre a natureza, as finalidades e os procedimentos da aprendizagem teatral é atravessada, como sabemos, pelas interrogações próprias dos processos educacionais e pelas surpresas inerentes à conquista do conhecimento nas artes.

Nesse sentido, percebemos a importância de que o estagiário estabeleça algum vínculo com a escola e com os profissionais que ali atuam. Refletindo sobre as possíveis relações entre universidade-escola, o estágio é um espaço oportuno para a troca de experiências, de compartilhamento bilateral de saberes. Para tanto, é necessário que a escola tome conhecimento sobre as ações realizadas nos estágios, que possa debater e se aproximar das práticas desenvolvidas pelos estagiários, e que o estagiário, por sua vez, compreendendo as demandas e estruturas da comunidade escolar, possa vincular seu projeto ao contexto específico da escola onde atuará.

Aspira-se que o estágio não se caracterize apenas como um espaço no qual o acadêmico realiza uma prática e depois se desliga da escola sem um retorno à comunidade escolar, mas que possa se configurar como um espaço de retroalimentação, no qual estagiários, professores, supervisores da universidade e da escola provoquem discussões sobre os processos de ensino/aprendizagem do teatro. Tal diálogo permite que os profissionais da escola conheçam aspectos variados do fazer teatral. A partir do reconhecimento das diferentes práticas que compõem o teatro, a possibilidade de fortalecimento da área é ampliada, posto que profissionais que desconhecem as especificidades do teatro - não só professores de outras áreas como também os gestores das instituições de ensino provavelmente não o valorizem justamente pelo desconhecimento do que efetivamente se faz em uma aula de teatro.

Para Mario Piragibe,

O ensino de teatro se apresenta em discussões sobre metodologia de ensino para alunos de diversas faixas etárias e entornos socioculturais, em considerações acerca do papel que pode desempenhar na escola de hoje [...]. Esse painel nos mostra com razoável clareza o quanto a arte e a linguagem do teatro se configuram como uma matéria de discussão sobre a natureza da prática docente, mas também sobre o tipo de ensino que se pretende construir na perspectiva da formação de um indivíduo emancipado. (PIRAGIBE, 2013, p. 10)

Na perspectiva apontada por Piragibe, de que as práticas de ensino/aprendizagem do teatro se configuram a partir de diferentes contextos educacionais e propõem um espaço formativo diverso daquele suscitado por outras áreas do conhecimento, busca-se expor as propostas metodológicas exploradas pelos acadêmicos do curso de Licenciatura em Teatro em suas práticas de estágio, refletindo sobre seus limites, possibilidades e descobertas.

\section{As metodologias de ensino e os temas abordados pelos estudantes}

Os Estágios Supervisionados também se configuram como a fase em que o estudante escolhe determinadas metodologias de acordo com seus interesses e repertórios, e desses em relação ao ambiente escolar no qual as atividades serão desenvolvidas. Segundo Desgranges (2015, p. 125): "o ensino de Teatro precisa ser pensado em tensão com as experiências artísticas de seu tempo, vinculando $\mathrm{o}$ processo de aprendizagem às realizações cênicas contemporâneas". Nesse sentido, após estudar metodologias diversas, das quais podemos citar: Jogos Teatrais, Jogos Dramáticos, Drama, Teatro do Oprimido, Peças Didáticas, além de diferentes procedimentos de criação contemporâneos, o acadêmico tem a liberdade para determinar qual metodologia, ou elementos de diferentes metodologias, serão experimentados na prática com os estudantes da escola. Para tanto, o licenciando elabora um projeto de estágio. A escrita do projeto serve para elucidar as propostas metodológicas, mas também para que o acadêmico exercite a justificativa de suas escolhas, encontrando suporte nas teorias teatrais e defendendo a pertinência das propostas, tendo em vista o contexto específico em que atuará na escola.

Relacionar teoria e prática é um exercício necessário ao futuro professor, especialmente na área de Artes, área que, muitas vezes, tem que justificar sua pertinência nos ambientes de ensino por parecer destituída de conteúdos, critérios de avaliação e aplicabilidade no dia a dia do educando. Além disso, 
é necessário que o estudante saiba reconhecer as teorias que embasam suas práticas promovendo que ele possa refletir sobre as propostas que serão desenvolvidas com propriedade, problematizando as respostas recebidas na prática e questionando seu próprio fazer docente.

O termo método descende do grego - metá, pelo, através e hodós, caminho - e significa, na perspectiva pedagógica, a unidade entre teoria e prática que compreende o ambiente educativo em face da realidade sócio-cultural na qual os sujeitos se inserem. Neste sentido, metodologia do ensino constitui-se em uma atividade de natureza bastante complexa que se torna objetiva somente quando é convertida em procedimento de ensino voltado para a superação do apriorismo, do dogmatismo e do espontaneísmo, com vistas à interação entre a cultura elaborada e a produção permanente do conhecimento. (KOUDELA; SANTANA, 2005, p. 146)

$\mathrm{Na}$ busca pelo compartilhamento dos diferentes caminhos traçados pelos licenciandos nas suas práticas, o I Encontro dos Estágios da Licenciatura em Teatro apresentou trabalhos distribuídos em quatro eixos temáticos, de modo a fomentar reflexões sobre as abordagens desenvolvidas pelos estudantes em seus estágios, procurando estabelecer paralelos entre as diferentes propostas, referências teóricas e contextos socioculturais. Será apresentado, na sequência, um breve panorama de cada um dos eixos.

$\mathrm{O}$ primeiro eixo ${ }^{2}$ reuniu estudantes que desenvolveram seus projetos a partir da abordagem do Drama ou do uso de alguma estratégia desse método. Como método de ensino do teatro, introduzido no Brasil pela professora e pesquisadora Beatriz Cabral nos anos de 1990, o Drama é um fazer teatral no qual os participantes emergem em uma situação fictícia, sugerida pelo condutor do processo, e agem como se fossem outras pessoas (seres ficcionais) ou como eles mesmos nessa situação - em um contexto ficcional - "[...] construindo uma narrativa a partir dos estímulos postos para serem explorados (textos, imagens, desafios, mistérios, conflitos, entre outros)" (PEREIRA, 2014, p. 70).

As três estagiárias que escolheram trabalhar com o Drama o fizeram, também, em função de terem selecionado como campo de estágio a Educação Infantil (com crianças entre 03 e 05 anos) e compreenderem que essa abordagem melhor se aproximava das especificidades do trabalho teatral com crianças mais novas. Um dos trabalhos buscou a aproximação de jogos tradicionais propostos em sala de aula com os jogos dramáticos, a partir da perspectiva de Machado e Rosman (1971), para a instauração de um ambiente lúdico e, posteriormente, a partir da estratégia do professor no papel (VIDOR, 2010), iniciou um processo de Drama que buscou incentivar a exploração do trânsito entre real e ficcional, típico das crianças, colocando-as como investigadores.

O segundo trabalho propunha que, por meio do Drama, as crianças explorassem a brincadeira de faz-de-conta experimentando materiais postos à sua disposição, colocando-as como exploradores de diferentes ambientes (florestas, deserto, mar, Lua, circo, entre outros). A estratégia do professor vivenciando diferentes papéis aliada à presença de outros personagens (atores convidados) contribuiu para a sustentação do ambiente lúdico. E o terceiro projeto, focou na figura do professor personagem, uma Cavaleira que possuía uma égua, estabelecendo, a partir dessa mediação e da participação de outros atores (como uma Pirata, uma Fada do sexo masculino) desconstruções de papéis de gênero aos quais as crianças, desde muito jovens, são expostas.

O segundo eixo ${ }^{3}$ foi composto por trabalhos que buscaram relacionar teatro, cinema e artes. Nesse eixo, uma das estagiárias desenvolveu experimentações básicas de jogo cênico, a partir do trabalho de Soares (2010), e da linguagem audiovisual, em um diálogo com o trabalho de Faria (2011), com turmas do 7. e 9. anos, propondo a adaptação de jogos teatrais para a criação de vídeos.

Já uma dupla de estagiárias, atuando na disciplina de Música, uma vez que essa era a linguagem artística explorada nessa escola de Ensino Médio (uma exceção às Artes Visuais), interessou-se pela exploração de linguagens artísticas distintas, buscando flexibilizar hierarquias do processo de ensino/aprendizagem e acolher os interesses artísticos dos alunos. A proposta das estagiárias destacou uma perspectiva política do fazer teatral a partir da elaboração da estrutura das aulas que enfatizou o modo como o teatro é (ou pode ser) feito. Segundo Lehmann (2007, p. 414), "não é pela tematização direta do político que o teatro se torna político, mas pelo teor implícito de seu modo de representação. [...] isso implica não só determinadas formas, mas também um modo de trabalhar específico". Nesse sentido, a partir de uma breve instrumentalização dos alunos com dispositivos diversos (instrumentos musicais, desenho, fotografia, vídeo, roteiros e jogos teatrais), os participantes se reuniram em núcleos desenvolvendo 
acontecimentos cênicos a partir de temas escolhidos coletivamente pela turma. Coube às estagiárias compreenderem como instigar os estudantes à autonomia necessária para esse modo de operar, estimulando a liberdade de escolha aliada ao rigor necessário ao desenvolvimento de um processo de ensino/aprendizagem em Artes.

Por meio de jogos teatrais, a partir dos trabalhos de Spolin $(2005,2007)$ e Koudela (2011) e de recursos do audiovisual, o terceiro trabalho apresentado no segundo eixo buscou promover a experimentação teatral junto a audiovisual como propulsora de processos artísticos na escola, com turmas do $6 .^{\circ}$ e $8 .^{\circ}$ anos. Propostas de trabalho de Moletta (2009) e Norton (2013) que trazem a pedagogia do audiovisual como possibilidade de criação artística, além de Bordwell e Thompson (2013), que apresentam um panorama sobre a linguagem cinematográfica, além de apontarem conceitos fundamentais para compreensão da linguagem, como: plano, montagem, mise-en-scène cinematográfica, serviram de referência para o desenvolvimento desse projeto.

No terceiro eixo ${ }^{4}$ reuniu-se trabalhos que desenvolveram a abordagem dos Jogos Teatrais com maior ênfase. Sobre essa abordagem, aponta Pupo (2005, p. 220):

[...] o sistema de jogos teatrais se dissemina amplamente de Norte a Sul a partir do final dos anos 70, graças a uma série de pesquisas acadêmicas em torno de suas potencialidades e ao oferecimento de um sem número de cursos de formação inicial e continuada a professores e coordenadores de oficinas teatrais. Essa ampla penetração do sistema entre nós se explica, entre outras razões, por sua própria estrutura. Ancorado no jogo tradicional de regras, patrimônio de todas as culturas em todos os tempos históricos, essa proposta reúne princípios de trabalho teatral passíveis de serem apropriados por indivíduos das mais diferentes origens socioculturais.

De modo geral, os estudantes de teatro possuem um grande repertório de jogos, uma vez que, em muitas disciplinas, eles são utilizados com diferentes finalidades. No momento da escolha das metodologias de trabalho para as práticas de estágio, os trabalhos de Spolin $(2005,2007)$ e Koudela (2011) aparecem como uma forte referência.

Dos trabalhos desenvolvidos nesse semestre, apenas um projeto trabalhou com a Educação de Jovens e Adultos (EJA) e, em sua prática, utilizou a abordagem dos Jogos Teatrais para buscar ampliar a interação e a comunicação entre os alunos adultos, uma vez que o estagiário percebeu nas aulas de observação que os adultos pouco conversavam entre si e apresentavam muita dificuldade de se relacionarem e se exporem diante do grupo. Um segundo trabalho, com turmas do $8 .^{\circ}$ e $9 .^{\circ}$ anos, na busca por promover um primeiro contato do grupo com a linguagem teatral, explorou a relação entre os Jogos Teatrais e conceitos de Constantin Stanislavski, referenciais presentes na sua formação anterior como Bacharel em Teatro e revisitada em seu estágio no curso de Licenciatura. A relação entre essas duas práticas é facilmente reconhecida pelos estudiosos do Método Stanislavski e ratificada por Pupo,

Spolin - visivelmente marcada pela influência de Stanislavski no período final de sua vida, quando enfatiza as ações físicas como eixo da formação do ator - formula seus dispositivos de aprendizagem de modo a promover a chamada fisicalização, ou seja, a preocupação em tornar reais lugares, objetos, ações e personagens. (PUPO, 2005, p. 219)

O terceiro trabalho desse eixo buscou desenvolver a capacidade do grupo de se relacionar, uma vez que foi observado um excesso de conflitos entre os estudantes na sala de aula, assim como proporcionar uma aprendizagem da linguagem teatral de forma coletiva, dado que a maior parte das crianças nunca teve contato com teatro. Esse projeto foi desenvolvido com duas turmas de $5 .^{\circ}$ ano, o que permitiu, também, uma comparação entre os dois processos. Em uma turma foi possível trabalhar a criação de pequenas cenas, enquanto na outra, os conflitos entre os estudantes não permitiram chegar a essa etapa. Outra referência utilizada nesse trabalho foi o livro Atividades Globais de Expressão, de Reverbel (2007), teórica, autora e professora de teatro, pioneira do Teatro/Educação no sul do Brasil.

Esse terceiro eixo se relaciona com o que aponta o Desgranges sobre o ensino do teatro:

O ensino do teatro, por sua vez, vem sendo proposto, nas mais diferentes instituições educacionais e culturais, calcado na prática com jogos de improvisação. Isso porque se compreende que, desse modo, o prazer de jogar se aproxima do prazer de aprender a fazer e a ver teatro, estimulando os participantes a organizarem um discurso cênico apurado, que explore a utilização dos diferentes elementos que constituem a linguagem teatral, bem como a apreender leituras próprias acerca das cenas 
criadas pelos demais integrantes do grupo. (DESGRANGES, 2015, p. 126)

Por mais que os estudantes tenham um repertório de jogos, muitas vezes falta um olhar apurado para o modo de organizarem seus planos de aula a fim de contemplarem as diferentes dimensões apontadas por Desgranges: fazer e ver, organizar um discurso cênico e realizar leituras dos materiais criados pelos colegas. Buscamos, nessa perspectiva dos jogos, incentivar os estagiários a estabelecerem conexões entre os jogos que compõem seus planos e a perceberem essas diferentes dimensões, em diálogo com as próprias indicações de Spolin de instruir o ato de fazer e avaliar coletivamente as propostas realizadas.

Por fim, o quarto eixo ${ }^{5}$ destacou propostas que trabalharam na perspectiva da interdisciplinaridade. Um dos trabalhos apresentados buscou explorar relações entre acrobacias e o aparelho circense bambolê, desenvolvendo conhecimentos das artes cênicas na aprendizagem de técnicas e elaboração de números circenses. Atenta ao conteúdo que vinha sendo desenvolvido pelo professor regente na disciplina de Educação Física, envolvendo acrobacias e técnicas circenses, a estudante aliou o interesse da turma a suas pesquisas na mesma área, destacando conteúdos teatrais. Aliando práticas e metodologias advindas de seus estudos teóricos, com destaque ao material de Bortoletto et al. (2011), ao seu repertório enquanto artista circense, a estagiária organizou o trabalho com os participantes finalizando com a apresentação do Circo Grilo Margarida reunindo os números circenses desenvolvidos pelo grupo ao longo das aulas.

Outro trabalho esteve centrado na busca por desenvolver escrituras cênicas de caráter (auto)biográfico a partir da performance e da criação de dramaturgias autorais com um grupo de alunos com frequência inconstante, em um estágio que também ocorreu na disciplina de Educação Física disciplina que, na determinada escola, é oferecida no contra turno e pode ser substituída por uma série de atividades realizadas pelos alunos, de curso preparatório ao vestibular à emprego. Apesar das dificuldades encontradas pelos estagiários, em decorrência da inconstância do grupo, o diálogo entre e biografia e performance fomentou práticas e debates na turma, formada apenas por alunas. Com suporte em Lehmann (2007) e Arfuch (2010), os estagiários encontraram na performer Marina Abramovic, referência apresentada por uma estudante da escola, um elo entre o conteúdo a ser proposto no estágio e os interesses do grupo. Instigadas pelas performances de Abramovic, as quais as alunas conheceram através das redes sociais, o grupo misturou ficção e realidade na criação de pequenas situações, destacando temáticas relativas ao contexto das adolescentes.

Ainda no quarto eixo, o último trabalho destacou o desenvolvimento de práticas iniciais de teatro com alunos sem conhecimento prévio da linguagem teatral, a partir das propostas de Spolin, com uma turma do 9. ${ }^{\circ}$ ano, culminando na criação de cenas que se utilizaram de contos de Luiz Fernando Veríssimo, apresentando outra perspectiva, até então não investigada no estágio, de utilizar um texto ainda que não dramático - para exploração de elementos do teatro (personagens, cenas, ação, uso de objetos cênicos, entre outros).

Cabe ressaltar que cada uma dessas mesas foi mediada por um professor do curso de Licenciatura em Teatro da $\mathrm{UFSM}^{6}$ que possuía alguma proximidade com as discussões propostas em cada um dos eixos, buscando, a partir da apresentação das práticas realizadas em campo, propor discussões que foram partilhadas pelo público presente no evento.

\section{Algumas considerações: aspectos políticos da interação universidade-escola}

As reflexões geradas nos debates promovidos pelo Encontro contribuíram para uma maior visibilidade do teatro como atividade artística, pedagógica e cultural na paisagem do território escolar. A presença dos professores das unidades educativas nesse evento se fez importante para que os futuros professores, ainda em formação, pudessem discutir e construir coletivamente saberes sobre a prática docente, desmistificando medos e preconceitos com o ambiente da escola, sobretudo, pública.

Eventos que possibilitam o compartilhamento sobre práticas realizadas no ambiente escolar promovem que outros estudantes de Licenciatura em Teatro, que se encontram nas fases iniciais do curso, possam refletir sobre a relação com a escola não apenas quando chegam no momento de realização dos Estágios Supervisionados, mas já nas primeiras fases do curso (acompanhando o evento, participando dos debates). Tal perspectiva promove que o estágio não seja algo restrito ao final do percurso formativo do futuro professor.

Analisando os diferentes materiais 
apresentados pelos estagiários, podemos perceber a diversidade de abordagens possíveis no estabelecimento de um processo de ensino/aprendizagem em Teatro. De propostas mais próximas à primeira infância, nas quais a criação teatral se aproxima do jogo de faz de conta, passando por propostas que envolvem relações com a linguagem audiovisual, friccionando essas fronteiras. Projetos que reafirmam o potencial dos jogos teatrais como possibilidade de iniciação ao trabalho teatral com diferentes faixas etárias, recriando novos caminhos a partir de jogos já bastante disseminados, e ainda propostas que dialogam com a cena contemporânea, que buscam suporte no circo, na performance, nas escrituras (auto)biográficas e na mobilização de hierarquias nos processos artísticos e pedagógicos.

Esse amplo leque de possibilidades leva-nos a perceber o quanto a escola não deveria se isolar das práticas artísticas produzidas fora de seus muros. Enquanto diferentes grupos e artistas exploram e pesquisam novos suportes para a criação cênica, parece-nos que as práticas realizadas na escola, muitas vezes, permanecem em um senso comum que relaciona o ensino do teatro aos modelos tradicionais de montagem de peças ou às aulas de jogos que muitas vezes se esvaziam em si mesmas.

Assim, o evento estimulou a formação de redes entre os estudantes através do reconhecimento dos projetos e interesses artístico-pedagógicos de seus colegas. $\mathrm{Na}$ aproximação de diferentes práticas possíveis de serem desenvolvidas no ambiente escolar, aos estagiários também foi apresentada a atuação do profissional de ensino como agente efetivo de um núcleo que compartilha modos de fazer em uma perspectiva de retroalimentação. A formação do professor - tanto na graduação quanto na continuidade formativa que se dá em campo também se faz na relação com os demais, na interação entre disciplinas e colegas. A perspectiva da retroalimentação é fundamental para que o professor não se torne um solitário no ambiente escolar. Através do evento foi possibilitado ao estudante de estágio o desenvolvimento de algumas competências no sentido da formação de parcerias por meio da aproximação a projetos de colegas.

Adentrando ao tema da formação continuada, é válido ressaltar a característica do I Encontro dos Estágios da Licenciatura em Teatro de formação continuada aos professores regentes e demais professores da rede pública que se interessaram em participar do evento. Tal perspectiva foi destacada na fala de um dos professores regentes ao salientar como o encontro estava promovendo importantes reflexões sobre a escola e o fazer docente, possibilitando um tempo de reflexão que não é constante nas atividades do dia-adia da escola. Para esse professor, os debates propostos o animaram a repensar não só suas práticas, mas também a possibilidade de conteúdos teatrais estarem permeando a atuação dos professores para além da disciplina de Artes.

O evento, assim, fortaleceu os laços com a comunidade escolar, oferecendo maior visibilidade do potencial extensionista inerente à prática artístico/pedagógica do Teatro. A participação e depoimentos dos professores enfatizaram a importância de que a universidade invista em eventos que aproximem os universos acadêmicos e escolares. Ao entrar em contato com diversos projetos, os professores que já atuam nas redes de ensino têm a oportunidade de conhecer práticas e propostas que podem alimentar seus próprios processos como docentes nas instituições de ensino. Desse modo, abre-se uma possibilidade, também, de que a universidade contribua efetivamente com a formação continuada dos professores que atuam nas redes da Educação Básica. Sabe-se da enorme diferença que marca os professores no âmbito universitário daqueles que trabalham dia-a-dia na escola, dessa forma, promover o compartilhamento das reflexões produzidas na universidade destaca uma dimensão política dos sujeitos interessados em um efetivo diálogo com a educação e o ensino.

\section{Notas}

1 Evento realizado com o apoio da Pró-Reitoria de Extensão da Universidade Federal de Santa Maria, através de edital FIEX-CAL, no dia 14 de junho de 2017, no Centro de Artes e Letras/UFSM.

2 Neste eixo foram apresentados os trabalhos: "Em busca de Flicts, uma viagem lúdica na Educação Infantil", de Maria Jade Pohl Sanches; "Da competição ao Drama: possíveis estratégias para a ampliação da experiência criativa", de Victória Strasser e "No reino da Cavaleira Docinho: em busca do professor personagem que brinca com relações de gênero", de Joseane Taís Dréa.

3 Fizeram parte do eixo os seguintes trabalhos: "O (re)conhecimento do ensino de teatro e do cinema como conteúdo de arte na escola", de Échelen Garcia Vaz; "Aulas de Teatro ou de Artes? O despertar das potências criativas através da horizontalização do saber", de Aline Maria Lauermann e Fernanda Abegg e "Em Cine Duque 
Teatro - abordagens pedagógicas e possibilidades criativas a partir do ensino do teatro e audiovisual", de Gelton Quadros da Rosa.

4 Compondo esse eixo estavam os trabalhos: "Iniciação à linguagem teatral com adultos na Escola Municipal de Ensino Fundamental Duque de Caxias", de João Batista Ribeiro Baptistello; "Iniciação ao jogo teatral na sala de aula", de Gilvani José Bortoluzzi e "Vamos jogar? Uma investigação de práticas pedagógicas possíveis a partir de jogos teatrais', de Ana Paula Marques.

5 Fizeram parte do quarto eixo os seguintes trabalhos: "Bambolê e acrobacia: relações entre Circo e Educação Física", de Natália Dolwitsch; "Tecendo novas escrituras cênicas e (auto)biográficas com grupos inconstantes: uma experiência na escola Margarida Lopes", de Julio César Aranda e Raquel Zepka Senna e "Jogos teatrais na escola: uma introdução aos conceitos de teatro", de Vagno Rossano Macedo Martins.

6 Prof. Dr. Diego de Medeiros Pereira, Profa. Dra. Raquel Guerra; Profa. Dra. Rossana Perdomini Della Costa Vellozo e Profa. Ma. Marcia Berselli.

\section{Referências}

ARFUCH, L. O espaço biográfico: dilemas da subjetividade contemporânea. 1 . $^{\mathrm{a}}$ ed. Rio de Janeiro: EdUERJ, 2010.

BORDWELL, D; THOMPSON, K. A Arte do Cinema: uma introdução. 1. ${ }^{\mathrm{a}}$ ed. Campinas, SP: Editora da Unicamp, 2013.

BORTOLETO, M. A. C.; PINHEIRO, P. H. G. G.; PRODÓCIMO, E. Jogando com o circo. 1. ${ }^{\mathrm{a}} \mathrm{ed}$. São Paulo: Fontoura, 2011.

\section{BRASIL. SECRETARIA DA EDUCAÇÃO} FUNDAMENTAL. Parâmetros Curriculares Nacionais. Arte. Brasília: MEC/SEF, 1997.

DESGRANGES, F. Metodologia de Ensino. Léxico de Pedagogia do Teatro. 1. ${ }^{a}$ ed. São Paulo: Perspectiva: SP Escola de Teatro, 2015.

FARIA. N. V. da F. A linguagem cinematográfica na escola: o processo de produção de filmes na sala de aula como prática pedagógica. $2011.90 \mathrm{f}$. Dissertação (mestrado). São Paulo: Universidade Estadual Paulista, Campus Presidente Prudente,
Faculdade de Ciências e Tecnologia 2011.

KOUDELA, I.; SANTANA, A. P. Abordagens metodológicas do teatro na educação. Ciências Humanas em Revista, São Luís, v. 3, n. 2, p. 145 194, 2005.

KOUDELA, I. Jogos Teatrais. 7. a ed. São Paulo: Perspectiva, 2011.

LEHMANN, Hans-Thies. O teatro pós-dramático. 1. ${ }^{a}$ ed. São Paulo: Cosac Naify, 2007.

MACHADO, M; ROSMAN, M. 100 Jogos Dramáticos. 1. ${ }^{a}$ ed. Rio de Janeiro: Athan, 1971.

MOLETTA, A. Criação de Curta-Metragem em Vídeo Digital: uma proposta para produção de baixo custo. 1. a ed. São Paulo: Ed, Summus, 2009.

NORTON, M. Cinema Oficina: técnica e criatividade no ensino audiovisual. 1. ${ }^{\mathrm{a}}$ ed. Niterói: Editora da UFF, 2013.

PEREIRA, D. Drama como uma possibilidade teatral na Educação Infantil. Revista aSPAs, São Paulo, v. 4, p. 68-79, 2014.

PIRAGIBE, M. Prefácio. TELLES, N. (org.). Pedagogia do Teatro: práticas contemporâneas na sala de aula. 1. a ed. Campinas, SP: Papirus, 2013.

PUPO, M. L. Para desembaraçar os fios. Educação e Realidade, Porto Alegre, v. 30, n. 2, p. 217-228, 2005.

REVERBEL, O. Jogos Teatrais na escola: atividades globais de expressão. 5. ${ }^{\text {a }}$ ed. São Paulo: Scipione, 2007.

SANTANA, A. P. Teatro e formação de professores. 1. ${ }^{\mathrm{a}}$ ed. São Luís: EDUFMA, 2000.

SOARES, C. Pedagogia do Jogo Teatral: Uma poética do efêmero. 1. ${ }^{a}$ ed. São Paulo: Hucitec, 2010.

SPOLIN, V. Improvisação para o Teatro. 5. ${ }^{\mathrm{a}} \mathrm{ed}$. São Paulo: Perspectiva, 2005. Jogos Teatrais na Sala de Aula. 1. ${ }^{\mathrm{a}}$ ed. São Paulo: Perspectiva, 2007. 
VIDOR, H. Drama e Teatralidade: o ensino do

2010.

teatro na escola. 1. ${ }^{a}$ ed. Porto Alegre: Mediação,

\section{Sobre os autores}

Diego de Medeiros Pereira: Doutor em Teatro pela Universidade do Estado de Santa Catarina (Udesc, 2015), Mestre em Teatro por essa universidade (Udesc, 2011) e Licenciado em Artes Cênicas, também pela Udesc (2008). Professor no Departamento de Artes Cênicas da Universidade Federal de Santa Maria (UFSM). Líder do Grupo de Estudos sobre Teatro e Infâncias (GETIs/CNPq) e do Laboratório de Criação (LACRI/CNPq). Possui projetos de ensino, pesquisa e extensão na área de Pedagogia do Teatro, com ênfases nas relações entre teatro e diferentes infâncias, na abordagem do Drama e na formação de professores. Ator, dançarino e encenador teatral.

Marcia Berselli: Possui graduação em Teatro pela Universidade Federal do Rio Grande do Sul (2012) e mestrado em Artes Cênicas pela mesma instituição (2014). Atualmente, desenvolve seu doutoramento no Programa de PósGraduação em Artes Cênicas (PPGAC/UFRGS) com a pesquisa "Abordagens à cena inclusiva: princípios norteadores para uma prática cênica acessível". Professora no Departamento de Artes Cênicas da Universidade Federal de Santa Maria. Líder do Grupo de Pesquisa Teatro Flexível: práticas cênicas e acessibilidade (CNPq/UFSM). Nos projetos de pesquisa, ensino e extensão que coordena, investiga práticas de criação com pessoas com e sem deficiência. Tem experiência na área de Artes, com ênfase em Teatro, atuando principalmente nos seguintes temas: teatro, processos de criação, educação, Contato Improvisação, práticas corporais, acessibilidade, cena e deficiência. Artista da cena.

Recebido em novembro de 2017.

Aprovado em março de 2018. 